\title{
llustração, escravidão e as condições de saúde dos escravos no Novo Mundo*
}

\section{Enlightenment, slavery and slaves' health conditions in the New World ${ }^{\star \star}$}

\author{
ALISSON EUGÊNIO \\ Professor adjunto do Uni-BH \\ Rua Diamantina, s/n, Lagoinha, $\mathrm{BH}$ \\ alissoneugenio@yahoo.com.br
}

Se a importação de africanos for proibida, (...) os fazendeiros e os escravos serão beneficiados.

Thomas Clarkson, An essay on the impolicy of the slave-trade.

RESUMO A partir da llustração, a escravidão começou a ser encarada por certos intelectuais como uma instituição injusta. Desse modo, eles contribuíram para que a sensibilidade social derivada do conceito de humanidade fosse aos poucos, em alguns círculos de letrados, estendida aos escravos, o que ajuda a compreender o porquê de, no seio da elite médica que atuou nas colônias situadas na América, terem surgido autores que elaboraram textos dedicados à orientação de como os grandes proprietários rurais

* Artigo enviado em 01/04/2008. Aprovado em 17/03/2009.

** Este texto é uma versão do quarto capítulo da minha tese de doutorado intitulada Reforma dos costumes: combate às más condições de saúde no Brasil do século XIX. São Paulo: USP, 2008 (Tese, doutorado em História)

1 CLARKSON, Thomas. An essay on the impolicy of the slave-trade. (1788). Apud: BEWELL, Alan. Medicine and West Indian slave trade. London: Pickering and Chatto, 1999, p.142. 
poderiam melhorar o tratamento dos seus negros, conciliando sentimento humanitário e interesse econômico.

Palavras-chave llustração, escravidão, medicina e saúde

ABSTRACT During the Enlightenment, the slavery started to be faced by certain intellectuals as an unjust institution. In this manner, in some circles of scholars, they had contributed to the social sensitivity derivative of the humanity concept was extended to the slaves. This helps to understand the reason why, among the medical elite that acted in the colonies in America, have appeared authors that wrote texts to orient the elite of farmers to improve the treatment of their slaves, putting toghter the human feelings and economic interests.

Keywords Enlightenment, slavery, medicine and health

Durante a colonização do Novo Mundo, os europeus revigoraram a escravidão depois dessa forma de organização do trabalho ter quase desaparecido na Baixa Idade Média, usando, além da população nativa dos territórios conquistados, milhões de africanos para viabilização da economia mercantil. Para isso, tais indivíduos foram forçados a atravessarem o Atlântico por meio de uma complexa atividade empresarial, conhecida como tráfico negreiro, que somente foi extinta ao longo do século XIX com as pressões do movimento abolicionista, que depois de ter sido inicialmente organizado na Inglaterra se expandiu aos poucos para os Estados Unidos, o Caribe e o Brasil.2

Enquanto essa atividade empresarial assegurou uma oferta abundante de mercadoria humana e com preços relativamente baixos, os grandes proprietários rurais preferiam, geralmente, explorar os seus escravos ao máximo com o menor custo possível, isto é, gastando o mínimo de recursos (alimentação, vestuário e moradia) para sustentá-los. ${ }^{3}$ Com efeito, as suas condições de vida eram muito precárias, razão pela qual morriam, na maioria

2 Entre os séculos XVI e XIX foram trazidos para a América em torno de 10 milhões de negros, de acordo com FLORENTINO, Manolo. Em costas negras. São Paulo: Cia. das Letras, 1997, p.23.

3 Vários historiadores comprovaram que os escravos foram mercadorias relativamente baratas até 1850, quando o tráfico foi definitivamente extinto, entre eles: FLORENTINO, Manolo. Em costas negras, p.78; JúNIOR, Caio Prado. História econômica do Brasil. 42ª .ed. São Paulo: Brasiliense, 1995, p.159 e CONRAD, Robert Edgar. Tumbeiros: o tráfico de escravos para o Brasil. São Paulo: Brasiliense, 1985, p.16. Um dos melhores testemunhos dessa lógica de exploração do trabalho escravo encontra-se na tese de David Gomes Jardim, defendida em 1847 na Faculdade de Medicina do Rio de Janeiro: JARDIM, David Gomes Algumas considerações sobre a higiene dos escravos. Rio de Janeiro, Faculdade de Medicina do Rio de Janeiro, 1847, p.12. (Tese, doutorado em Medicina). Uma síntese da referida lógica foi elaborada por SOMARRIBA, Maria das Graças G. A medicina no escravismo colonial. Textos de Sociologia, Belo Horizonte/UFMG, p.7-8, 11, v.1, 1984. 
das vezes, precocemente vitimados por doenças provocadas pelos mais diversos fatores, o que, pelo menos desde o final do século XVII, chamou a atenção de médicos que atuavam nas colônias.

Entre eles, o primeiro a retratar os problemas de saúde dos escravos no Novo Mundo foi Thomas Traphan em uma obra intitulada A discourse of the state of health in the Island of Jamaica, publicada no ano de 1679 em Londres. Nela descreveu as moléstias mais comuns no Caribe e expôs os recursos terapêuticos para remediá-las, sem, no entanto, questionar os altos índices de mortalidade dos seus habitantes, muito menos os dos que estavam submetidos ao cativeiro. ${ }^{4}$

Na América portuguesa, o mesmo foi feito pelo cirurgião Luís Gomes Ferreira, na obra Erário mineral, escrita com base na sua atuação em Minas Gerais entre o início da década de 1710 e o início da década de 1730 aproximadamente e publicada no ano 1735 em Lisboa. No decorrer dela, quando muito, em raras passagens, evocou o sentimento religioso da sociedade colonial para lamentar "o pouco temor de Deus" daqueles que deixavam "morrer ao desamparo" tanto escravo, referindo-se à negligência de muitos senhores com a saúde dos seus negros. ${ }^{5}$

Mesmo assim, esse texto e o de Traphan, embora não tivessem sido voltados exclusivamente às doenças dos escravos e limitarem-se a descrevê-las expondo apenas meios para saná-las, apresentaram uma preocupação inaugural com as condições de saúde desses indivíduos. Preocupação que, no decorrer da segunda metade do século XVIII, aos poucos foi sendo associada pelos médicos, entre outros letrados, à crítica ao modo predatório de se explorar a sua mão-de-obra (excesso de trabalho combinado com alimentação inadequada, vestimenta insuficiente e moradia insalubre), com o objetivo de reduzir os seus altos índices de óbitos.

Daí em diante, as publicações na área de medicina dedicadas aos problemas de saúde da população escrava começaram a apresentar pelo menos duas novidades em relação às anteriores: a exposição de meios para o combate preventivo contra as enfermidades de tal população e a problematização da sua alta mortalidade. O surgimento dessas novidades está relacionado com os seguintes fatores: o aumento da demanda por escravos, o encarecimento dos seus preços na Guerra dos Sete Anos (1756-1763), a formação do movimento antiescravista na Inglaterra e o amadurecimento da concepção pragmática sobre a função social da ciência promovido durante a llustração. ${ }^{6}$

4 TRAPHAN, Thomas. A discourse of the state of health in the island of Jamaica de Thomas Traphan (1679). Apud: BEWELL, Alan. Medicine and West Indian slave trade.

5 FURTADO, Júnia Ferreira. (org.) Erário Mineral, de Luís Gomes Ferreira. Belo Horizonte: Fundação João Pinheiro, 2002, p.610

6 Esses fatores foram analisados por MARQUESE, Rafael de Bivar. Feitores do corpo, missionários da mente: senhores, letrados e o controle dos escravos nas Américas. São Paulo: Cia. das Letras, 2004, cap.2. 
Esse último foi decisivo para impulsionar o interesse médico pelas condições de saúde da população em geral e em particular a dos escravos, ao destacar a possibilidade de o homem resolver grande parte dos seus problemas por meio do progresso do seu conhecimento, que cada vez mais estava sendo considerado nos círculos intelectuais um importante instrumento e um pré-requisito para melhorar a vida humana e aprimorar a sociedade. Tal possibilidade, que já havia sido enunciada desde o final do Renascimento e reforçada com o avanço científico do século XVII, estimulou a formação de uma nova sensibilidade marcada pelo sentimento de compaixão em relação às vítimas dos males da humanidade e pela exigência de um conjunto de ações destinadas a mitigar os seus sofrimentos. ${ }^{7}$

Imbuídos dessa compaixão, que a partir da segunda metade do século XVIII veio a ser um elemento fundamental de compreensão dos problemas da vida social, muitos dos escritores da época, sob o impulso do pensamento ilustrado, desenvolveram o argumento de que as sociedades deveriam mobilizar as suas forças para a construção de um mundo melhor por meio da ciência, da justiça e da solidariedade, combatendo os infortúnios da condição humana. Com isso, começou a formar-se o que pode ser chamado de solidariedade laica, expressa pela noção de benevolência, a partir da qual a compaixão pelos outros deixou de ser apenas um elemento da piedade religiosa para ser um fundamento da forma de se encarar as adversidades sociais. ${ }^{8}$

Assim, no artigo sobre o conceito de humanidade, "um sentimento de benevolência por todos os homens", inserido na Enciclopédia organizada por Denis Diderot e Jean d'Alembert, as pessoas de "alma grande e sensível" são chamadas a "percorrer o universo para abolir a escravidão, a superstição, o vício e a desgraça". ${ }^{9}$ Dessa maneira, os que se identificaram com esses ideais humanitários lentamente passaram a conceber a escravidão como uma forma injusta de organização do trabalho, rompendo com a sua legitimidade, até então assegurada por "uma rede de idéias tecida desde a Antiguidade", que a havia transformado em um elemento natural da vida social. ${ }^{10}$

Conseqüentemente, a partir desse período surgem textos colocando em questão na agenda da llustração os seus fundamentos, como a clássica obra de Montesquieu, Do espírito das leis, publicada em 1748, para cujo autor "a escravidão não é boa por sua natureza", por ser "tão contrária ao

7 A publicação do texto de Francis Bacon intitulado O progresso do conhecimento em 1605 é um indicador da nascente convicção de que a ciência poderia exercer um papel primordial para a melhoria da vida humana.

8 Conforme mostrou Felipe Fernandez Armesto ao longo do seu estudo dedicado à historicidade do conceito de humanidade, ARMESTO, Felipe Fernandez. Do you think you re human: a brief history of humankind. Oxford: Oxford University Press, 2004

9 DIDEROT e D'ALEMBERT. (orgs.) Encyclopédie ou dictionnaire raisonné des sciences, des arts et métiers. $2^{\mathrm{a} e d .}$ Lucques: Chez Vicent Giuntini, tome VIII, 1766, p.285.

10 Cf. ROCHA, Antônio Penalves Idéias antiescravistas da llustração na sociedade escravista brasileira. Revista Brasileira de História, v.20, n.39, p.45, 2000. 
direito civil quanto ao direito natural", uma vez que "todos os homens nascem iguais". ${ }^{11}$ Aos poucos, com as repercussões dessa obra, aparecem outros textos igualmente detratores desse costume tão antigo quanto à guerra, conforme lembrou Voltaire, no artigo sobre os escravos inserido no seu Dicionário filosófico (1763), ao criticar a naturalidade com a qual continuava sendo praticado na cultura ocidental. Artigos escritos por Jaucourt sobre escravidão (1755) e tráfico de escravos (1765) publicados na Enciclopédia dirigida por Denis Diderot e Jean d'Alembert, a História filosófica e política dos estabelecimentos e do comércio dos europeus nas duas Índias de Raynal, Reflexões sobre escravidão dos negros de Condorcet, ambas editadas em 1781, e Um ensaio sobre a imprudência do tráfico de escravos, de Thomas Clarkson lançado em 1788 são alguns dos mais expressivos.

Com a crítica filosófica desses autores, iniciou-se um processo (que durou até o final do século XIX desmantelando a sociedades escravistas no Ocidente) de desmontagem dos pilares sobre os quais a organização da produção do trabalho escravo estava fundamentada. Nesse mesmo processo, marcado pela recriação da escravidão em um contexto de aumento da demanda de mão-de-obra nas áreas exportadoras de alimentos e insumos em grande escala para a Europa, como no Brasil, foram publicados vários textos de medicina cujos autores, ao transformarem as doenças da população escrava em objeto permanente de estudo, enquanto durou a escravidão, se dedicaram a divulgar conhecimentos que poderiam reduzir a incidência delas e, com efeito, diminuir os altos índices de óbitos no cativeiro.

Entre eles destacam-se alguns editados sob a forma de manuais didáticos destinados aos senhores que tinham acesso à leitura. A partir deles, estes poderiam aprender a curar as enfermidades mais comuns dos seus escravos e, principalmente, como preveni-las, o que demandaria uma reforma do costume predominante no modo de exploração da mão-de-obra desses indivíduos. Isso porque, sem questionar a escravidão, os autores dos manuais escritos com a finalidade acima mencionada apontaram a lógica de se explorar a mão-de-obra cativa ao máximo com o menor custo possível como a principal fonte de que emanavam as causas de grande parte do obituário dos negros, argumentando que a vida útil deles poderia aumentar por meio de uma forma menos desumana de administrá-los e da utilização eficiente do saber médico.

Para isso, apresentaram um conjunto de propostas para tornar a administração do trabalho escravo compatível com o conceito de humanidade do pensamento ilustrado e com a noção de interesse, relacionada cada vez mais com as aspirações econômicas, em voga no século XVIII, ${ }^{12}$ as

11 MONTESQUIEU. Do espírito das leis. São Paulo: Martin Claret, 2007, p.249, 251, 254.

12 De acordo com MARQUESE, Rafael de Bivar. Feitores do corpo, missionários da mente, p.90-92, o binômio humanidade e interesse serviu como base para os letrados elaborarem textos em várias partes da América, desde 
quais podem ser resumidas no seguinte: alimentá-los, vesti-los e alojá-los adequadamente, ampará-los quando estivessem enfermos, exigir deles tarefas proporcionais as suas forças, conceder a eles descanso necessário para se revigorarem e restringir o seu consumo de cachaça.

Com essas propostas, os médicos que escreveram sobre esse assunto, defendendo a humanização da exploração da mão-de-obra cativa, contribuíram para inaugurar uma inédita preocupação com os corpos dos escravos que repercutiu na mentalidade senhorial à medida que os ataques à escravidão foram se acumulando e, sobretudo, quando o tráfico que a abastecia foi abolido. Um dos primeiros entre eles que se empenharam para divulgar idéias destinadas a reformar os costumes praticados na administração da população escrava foi James Grainger. Autor de um ensaio sobre as doenças mais comuns das Índias Ocidentais, em particular as dos negros, publicado em Londres no ano de 1764, justificou a sua publicação com essas palavras:

It has often been matter of astonishment to me, that among the many valuable medical tracts which of late years have been offered to the public, no one has been purposely written on the method of seasoning new Negroes, and the treatment of Negroes when sick: and yet the importance, if not the dignity of such a work, must appear obvious to all who are in the least acquainted with the West Indies. For it is a melancholy truth, that hundreds of these useful people are yearly sacrificed to mistake in these two capital points. To supply this defect and to enable those who are instructed with the management of Negroes, to treat them in a more scientifically manner than has hitherto been generally practiced, is the principal design of the present Essay. ${ }^{13}$

Partindo dessa justificativa, ele dedicou-se a convencer os fazendeiros de que, diante dos ataques à escravidão e dos seus possíveis efeitos sobre a legitimidade da importação de africanos, era mais prudente reformar os padrões de administração do trabalho escravo e recorrer à assistência médica para "dessa forma salvar várias vidas valiosas", o que seria muito "agradável para a humanidade" e mais vantajoso para a prosperidade das suas fazendas, porque "o preço dos escravos estava cada vez mais exorbitante". ${ }^{14}$ Com esse objetivo, propôs aos senhores que "tratassem os seus escravos como seres humanos", para evitarem a sua morte precoce, lembrando-os de que se o seu "próprio interesse" e o sentimento humanitário

a llustração, propondo uma reforma da administração do trabalho escravo.

13 GRAINGER, James. An essay on the more common West Indian diseases, and the remedies which that country itself produces. To which are added some hints on the management of negroes. (1764). Apud: BEWELL, Alan. Medicine and West Indian slave trade, p.279.

14 GRAINGER, James. An essay on the more common West Indian diseases, and the remedies which that country itself produces..., p.279. Esse aumento de preços estava sendo estimulado pela dificuldade e os ricos do transporte de africanos no Atlântico norte devido às guerras que envolveram a Inglaterra e a França desde a Guerra dos Sete Anos (1756-1763) até a Independência dos Estados Unidos. 
não fossem suficientes para agirem assim, "a legislação poderia obrigá-los" como ocorria nas colônias francesas. ${ }^{15}$

Tendo feito essa advertência, James Grainger recomendou que as condições de vida da população cativa fossem melhoradas, por meio de alimentação nutritiva, vestimenta adequada, alojamento salubre, descanso suficiente e moderações nos castigos, para ela ficar menos vulnerável às doenças. Essas recomendações foram reafirmadas, mostrando como a medicina poderia exercer um papel relevante na economia escravista, em textos médicos até o crepúsculo da escravidão no Ocidente, como forma de combate à exploração predatória da mão-de-obra escrava, da qual derivavam, segundo os seus autores, as causas de várias enfermidades que tantos estragos provocavam no cativeiro.

No espaço colonial português, um dos primeiros textos que esboçaram alguma preocupação com os altos índices de mortalidade da população escrava, embora apenas em raras passagens, foi escrito por José Antônio Mendes com base nas suas atividades como cirurgião em Minas Gerais, onde atuou durante 35 anos no Hospital do Contrato Diamantino e no dos Dragões da Guarnição do Serro Frio. Trata-se de um manual médico publicado em Lisboa no ano de 1770 para circular na América portuguesa, como forma de atenuar a escassez de agentes devidamente habilitados nas artes de curar no seu vasto interior, como o seu próprio título revela: governo de mineiros muito necessário para os que vivem distantes de professores seis, oito, dez, e mais léguas, padecendo por esta causa os seus domésticos e escravos queixas, que pela dilação dos remédios se fazem incuráveis e as mais das vezes mortais. ${ }^{16}$

Os problemas que, entre outros fatores, motivaram o seu autor a elaborá-lo, bem como as expectativas dele concorrer para diminuição dos sofrimentos provocados por tantas moléstias que grassavam na Colônia, foram expressos pelo capitão-mor José Xavier de Valladares e Souza em um soneto laudatório, de acordo com o padrão de apresentação de textos ainda vigente na época: ${ }^{17}$

\footnotetext{
Nessas vastas regiões, que indica a fama

No lenho, a que deu nome a brasa viva,

Reina absoluta a parca executiva,

Com a mirrada mão mortes derrama.
}

15 GRAINGER, James. An essay on the more common West Indian diseases, and the remedies which that country itself, p.290. Ao reportar-se ao espaço colonial francês, ele refere-se ao Code Noir (1685); uma legislação específica que impôs obrigações aos senhores no trato com os seus escravos, como o sustento material e espiritual adequado.

16 MENDES, José Antônio. Governo de mineiros... Lisboa: Oficina de Antônio Rodrigues Galhardo, 1770.

17 SCOTTI, Eliana Muzzi. Ouro, poesia e medicina: os poemas introdutórios ao Erário Mineral. In: FURTADO, Júnia Ferreira. Erário Mineral, p.31-32. 
O Etíope boçal enfermo clama,

O Índio bruto geme em febre ativa,

E aflita com o mal, que a inércia aviva,

Em vão pela Arte a Natureza chama.

Mas já provém remédio a tanto dano

Este livro, que expõe, sábio, e profundo,

Auxílio pronto ao débio corpo humano:

Em que com fácil método jucundo

A rebater da parca o golpe infano

Ensina novo Apolo a novo Mundo. ${ }^{18}$

No Proêmio da sua obra, José Antônio Mendes explicita as razões pelas quais a elaborou: "A torpeza é, dizia o famoso Sêneca, não deixarem os homens no mundo mais testemunhos de que sua vida", motivo pelo qual precisam se esforçar para "não viverem somente para si, mas também para os demais", divulgando informações "que podem ser úteis para muitos". Eis por que "a utilidade deve ser o escopo dos escritos". ${ }^{19}$

Com esse argumento, ele se justifica afirmando que não escreveu o Governo de mineiros "por vaidade", ou por uma possível "glória da posteridade". Ao contrário, o fez para mostrar como deviam ser preparados e usados os remédios contra as "enfermidades com o método racional", e assim colaborar para evitar os erros que levavam muitos à sepultura quando precisavam se tratar, ou a seus domésticos e escravos, na ausência de médicos. ${ }^{20}$

Visando a essa meta, arrolou algumas das principais doenças da população em geral e, em particular, as dos negros, ao longo de 15 capítulos que explicam o que fazer para remediá-las. Em um deles, no sexto, dedicado às "feridas em geral", os senhores são orientados a adquirirem agulhas e tesouras de cirurgia para fecharem alguns ferimentos dos seus escravos, pois, conforme explicou: "O custo é tão pouco que não podeis dar desculpa para não teres em vossa lavra ou roça". ${ }^{21}$

Ao fazer essa orientação, sem criticar a negligência senhorial com os cuidados necessários para a conservação da saúde da escravaria, o autor da obra em tela sutilmente procurou explicar que determinados gastos eram compensados pelos benefícios com eles obtidos. Dessa forma, criticou a pouca preocupação que havia com a alimentação dos escravos, bem como com o seu consumo de "uma tão depravada bebida a que chamam

18 MENDES, José Antônio Governo de mineiros..., p.VII.

19 MENDES, José Antônio Governo de mineiros..., p.VIII.

20 MENDES, José Antônio Governo de mineiros..., p.XIII-XIV.

21 MENDES, José Antônio Governo de mineiros..., p.29. 
cachaça", ambas responsáveis por tantas enfermidades que os debilitavam ou os levavam à morte precocemente..$^{22}$

Uma delas, o escorbuto, era tão comum que o levou a fazer o seguinte comentário: "Ela nessas Minas mata muita gente", especialmente os submetidos aos rigores da vida no cativeiro, devido aos "alimentos grosseiros, crassos e corruptos de que se usa na maior parte dessa América dar-se aos negros", os quais já desembarcam freqüentemente afetados por esse mal, por serem sustentados no mar de mantimentos não só grosseiros, mas muitas vezes meio podre". ${ }^{23}$ Em sua opinião, isso explica a debilitação de boa parcela de escravos miseravelmente empregados "nos serviços de minerar" do "contrato dos diamantes", os quais, entre os demais, eram os que mais precisavam de resistência física em função das características dessa árdua atividade. ${ }^{24}$

No espaço colonial francês, um dos primeiros textos médicos cujo autor empenhou-se para divulgar conhecimentos que poderiam contribuir com a diminuição dos altos índices de mortalidade dos escravos foi Observations sur les maladies des nègres, escrito por Jean Barthelemy Dazille com base na sua experiência profissional em São Domingos, publicado no ano 1776 em Paris. ${ }^{25}$ Essa obra representa os primeiros esforços feitos nas colônias francesas do Novo Mundo pelos médicos e pelo Estado para a redução da incidência de tantas doenças nos escravos provenientes da forma predatória como o seu trabalho até então era explorado e, com efeito, para melhorar a situação econômica da região após a sua desestabilização provocada pela Guerra dos Sete Anos (1756-63).

Tal esforço foi devidamente justificado na sua introdução em uma longa passagem com o argumento de que a saúde da população é um fator primordial para o progresso econômico:

A população das Colônias determina-Ihes o grau de prosperidade. Se ela é numerosa produz força e riqueza; se fraca ou medíocre, ela indica igualmente pobreza e frouxidão. Todas as Colônias geralmente existem, ou devem existir, debaixo destas proporções: força e riqueza. Estes são os dois grandes objetos do seu destino. A riqueza reflui no Reino e concorre poderosamente para sua prosperidade geral; a força segura estas vantagens contra os inimigos de fora, independentemente dos socorros da capital, sempre incertos e tardos. Não é especialmente senão em uma população abundante de Negros que as Colônias acham a origem primitiva da sua opulência, por que sem Negros nada de cultura, nada de produtos, nada de riquezas. Uma Colônia unicamente povoada por Europeus pode bem fazer-se, depois de uma longa série de anos, Colônia de força, mas não passará disso; a riqueza não será jamais da sua repartição:

22 MENDES, José Antônio Governo de mineiros..., p.69.

23 MENDES, José Antônio Governo de mineiros..., p.85.

24 MENDES, José Antônio Governo de mineiros..., p.86.

25 DAZILLE, Jean Barthelemy. Observações sobre as enfermidades dos negros. Trad. Antônio José Vieira de Carvalho. Lisboa: Tipografia Arco do Cego, 1801. É a partir dessa tradução que sua análise será feita nessa pesquisa. 
tal tem sido o Canadá. Depois disto se vê que a introdução dos negros em uma Colônia é o maior meio e fundamental da sua prosperidade; o que a conservação destes entes desgraçados é o que faz este meio eficaz. Procurar as causas das enfermidades que os afetam, seguir estas enfermidades no seu princípio, progresso e terminação indicando os meios de as remediar, formar um resultado que tenda a impedir a despovoação espantosa da espécie, é ocupar-se do que utiliza aos colonos em particular, ao Comércio da Nação em geral e à prosperidade do Estado. ${ }^{26}$

Com essas palavras, Dazille tentava fazer os colonos reconhecerem que a diminuição dos altos índices de mortalidade dos seus negros dependeria da sua compreensão da necessidade da humanização dos seus métodos de exploração do trabalho escravo. Assim, esperava que eles adotassem algumas medidas destinadas ao melhoramento das condições de vida da sua escravaria, o que seria "útil para os seus interesses" e, ao mesmo tempo, como "um motivo mais nobre e satisfatório para os seus corações", também seria um "ato de humanidade e de beneficência". ${ }^{27}$

Para isso, tentou convencê-los de que os seus escravos morriam precocemente, devido principalmente à nefasta combinação entre "um insuficiente alimento, falta de vestidos e um trabalho superior às suas forças", que, junto com as suas deploráveis habitações, em geral desprovidas das mínimas regras de higiene, provocavam febres, disenteria, verminoses, distúrbios gástricos e pulmonares, entre outras enfermidades. ${ }^{28}$ Sendo assim, ele explicou o seguinte: "A primeira causa dessas diferentes moléstias provém do seu alimento, que consiste em raiz de mandioca grosseiramente pisada, feita em bolo muitas vezes mal cozido". Esse bolo, em certas colônias, é acrescido de substâncias animais e de outros vegetais fornecidos por alguns fazendeiros, como em Minas Gerais, onde, segundo o tradutor da sua obra,

usam os negros de diferente alimento, porque em lugar da mandioca eles têm o milho, que depois de moído em moinhos e peneirado o cozem simplesmente com água, mexendo-o até o ponto de se formar uma massa em boa consistência, a que chamam angu, que é o pão ordinário às suas comidas: estas são geral e cotidianamente o feijão negro cozido e temperado com gordura de porco; algumas vezes também é da sua repartição a carne; outras vezes da própria indústria eles fazem uma mistura de carne com plantas emolientes, de que o País abunda, como são: o caruru, o giquiri, o oropronobis, lobolobo, o quiabo, etc., a qual mistura é carregada de pimenta do mesmo País, que chamam jembe. ${ }^{29}$

26 DAZILLE, Jean Barthelemy. Observações sobre as enfermidades dos negros, p.15-16.

27 DAZILLE, Jean Barthelemy. Observações sobre as enfermidades dos negros, p.16.

28 DAZILLE, Jean Barthelemy. Observações sobre as enfermidades dos negros, p.27.

29 DAZILLE, Jean Barthelemy. Observações sobre as enfermidades dos negros, nota n.2, p.29. 
Mas, conforme observou: "A miséria ou outras circunstâncias obrigam" a maioria deles a fornecer aos seus cativos apenas aquele bolo, que, por ser "insípido, uniforme, mal preparado e não fermentado, produz nos humores a putrefação [causadora] das moléstias acima indicadas". ${ }^{30}$

Em relação ao vestuário dos negros, o descaso dos seus senhores com esse item era tão evidente que foi usado por Voltaire na composição de uma imagem perversa da escravidão para, junto com outras calamidades da época, ilustrar a miséria humana e questionar a hipótese dos filósofos otimistas de que se vivia no melhor dos mundos possíveis. Isso foi feito em um romance publicado em 1759, no qual o seu protagonista, Cândido, durante sua passagem pelo Suriname, ao se espantar com o estado horrível de um escravo, a quem faltava uma mão e uma perna e quase toda roupa, e perguntá-lo a razão disso, este the respondeu que era costume dar-lhes por única vestimenta ceroulas de algodão duas vezes por ano, cortar-lhes a mão cujo dedo fosse triturado pela mó do engenho e decepar uma das suas pernas se tentassem fugir. ${ }^{31}$

Com efeito, em uma região onde ocorriam bruscas variações climáticas, "tão freqüentes e rápidas", como observou Dazille, "os negros quase sempre mal vestidos" ficavam mais vulneráveis às doenças respiratórias que desgraçadamente engrossavam as suas taxas de óbitos.

Quanto ao problema do excesso de exploração da sua mão-de-obra, esse autor explica que "a pouca liberdade" a eles concedida "para seus deleites" determinava o principal fator do "rigor da sua escravidão". Pois o trabalho a que estavam sujeitos era "quase contínuo, e muitas vezes penoso, e superior à suas forças", conforme os seus senhores exigiam deles, "atendendo bem pouco aos seus interesses". ${ }^{32}$

Como se tudo isso não bastasse para reduzir a sua vida útil, eles eram muitos afeitos, segundo Dazille, à "libertinagem", pois, para satisfazê-la, iam "procurar longe, durante a noite, o objeto dos seus desejos, roubando desse tempo o único descanso que poderiam tomar". Era nessa oportunidade que consumiam grande quantidade de "licores fortes", como uma água ardente de cana de açúcar, igualmente "bem conhecida no Brasil, especialmente em Minas", onde também era bastante apreciada, o que concorria para debilitá-los ainda mais. ${ }^{33}$

Enfim, advertiu o autor: "Homens mal vestidos, mal nutridos, expostos a todas as injúrias do ar, sujeitos a um trabalho quase contínuo e entregues quase sem medida às inclinações dos deleites sensuais e dos licores fortes, não podem conservar a sua saúde". Por esse motivo, "eles não resistem

30 DAZILLE, Jean Barthelemy. Observações sobre as enfermidades dos negros, p.29-30.

31 VOLTAIRE. Cândido ou o otimismo. (1759). Trad. Miécio Tati. Rio de Janeiro: Ediouro, 1988, p.69-70.

32 DAZILLE, Jean Barthelemy. Observações sobre as enfermidades dos negros, p.31.

33 DAZILLE, Jean Barthelemy. Observações sobre as enfermidades dos negros, p.31 e 32. 
muito tempo", resultando na sua "despovoação espantosa, tão tocante a todo observador, que tanto importa impedir", em favor da humanidade, dos interesses materiais dos seus proprietários, da prosperidade econômica colonial e da metrópole. ${ }^{34}$

Por tudo isso, após expor os meios de curar as doenças mais comuns da população escrava, com quais remédios e de que forma deveriam ser preparados, bem como o que precisava ser feito para melhorar as suas condições de vida e de trabalho, na conclusão do seu livro exortou os "habitantes das Colônias" para "aliviar a desgraçada humanidade", ao "adoçar o rigor da sorte dos seus escravos", inspirados pelo sentimento de benevolência e pelos seus próprios interesses materiais. Pois, assim, "terão a vantagem de conservá-los mais tempo" e "mais úteis" pela maior inclinação que terão à "fidelidade". ${ }^{35}$

Em outras palavras, melhorando as condições de vida da população cativa, os seus proprietários adequariam a exploração da sua força de trabalho aos anseios humanitários de uma época cujos escritores identificados com o pensamento ilustrado passaram a exigir mais compaixão para com o próximo. Além disso, tal melhoria poderia tornar os negros menos resistentes ao cativeiro, diminuindo as tensões entre senhores e escravos inerentes às sociedades escravistas.

Esse argumento, em que o sentimento filantrópico articulado à noção de interesse econômico é reclamado para humanizar a exploração da mão-deobra dos negros e melhor atender às vantagens materiais dos colonos e às do Estado, pode ser compreendido como um exemplo do que David Brion Davis chamou de "ambivalência do racionalismo". Com essa expressão ele explica que "muitas idéias básicas do lluminismo" foram usadas pelos defensores do trabalho escravo contra os apelos abolicionistas então em processo de amadurecimento no Ocidente. ${ }^{36}$

Isso porque Dazille, como a maioria dos médicos que escreveram sobre esse assunto, era uma espécie de savant du ancien régime. Isto é, "um intelectual que, organicamente inserido nos aparelhos de Estado, aceitava a lógica e os valores de uma sociedade hierarquizada, estabelecida e organizada por ordens, classes e corpos diferenciados pelas dignidades, honras e onipresenças do privilégio". Afinal, esse autor atuou durante anos como cirurgião-mor das tropas de Caiena, dos hospitais da llha de Bourbon e da guarnição naval de São Domingos. ${ }^{37}$

34 DAZILLE, Jean Barthelemy. Observações sobre as enfermidades dos negros, p.32. Essa evocação do sentimento humanitário combinada com interesse econômico é realizada no seu texto, principalmente na p.16.

35 DAZILLE, Jean Barthelemy. Observações sobre as enfermidades dos negros, p.175

36 DAVIS, David Brion. O problema da escravidão na cultura ocidental. Rio de Janeiro: Civilização Brasileira, 2001, p.435

37 Definição elaborada por Vicenzo Ferrone na obra organizada por FERRONE, Vicenzo. O homem de ciência. In: VOVELLE, Michel. (org.) O homem do lluminismo. Lisboa: Editorial Presença, 1997, p.159. 
Assim, inserido em uma sociedade com tais características, procurou se mostrar digno das mercês do rei, produzindo um manual médico, que, com o objetivo de divulgar meios que pudessem colaborar para reduzir a mortalidade dos escravos, poderia "ser de muito proveito". Foi o que concluiu A. Petit, regente da Faculdade de Medicina da Universidade de Paris, em resposta ao ministro da marinha que o incumbiu de avaliá-lo, motivo pelo qual julgou que o seu autor merecia a "proteção" da Coroa. ${ }^{38}$

O mesmo pode ser dito sobre o tradutor do texto de Dazille, Antônio José Vieira de Carvalho, que, ocupando o posto de cirurgião-mor do Real Hospital Militar de Vila Rica desde 1781, tentava obter a patente de capitão com o respaldo do governador Bernardo José de Lorena que a seu respeito disse ao rei:

Como em todo o meu governo tem desempenhado excelentemente as suas obrigações, tratando dos doentes com amor, tanto no Hospital Militar, quanto no da Misericórdia, e sendo muito instruído em todos os conhecimentos necessários da sua arte, na língua francesa, e mostrando por documento ter introduzido nos mesmos hospitais o uso de vários gêneros do País com bom sucesso, evitando assim alguma despesa da Real Fazenda; a sua honrada e distinta conduta lhe tem merecido a estimação geral, e os tão justos títulos me parecem de qualquer honra e mercê própria da justiça e grandeza de sua majestade. ${ }^{39}$

O conteúdo desse documento remete ao sistema régio de mercês. Uma de suas marcas principais era uma espécie de ciclo de retribuições mútuas, a partir do qual a Coroa concedia alguns privilégios a quem defendesse os interesses do Estado. Isso permite vislumbrar alguns aspectos do esforço do mencionado cirurgião-mor para verter para a língua portuguesa a obra Observations sur les maladies des nègres, que, segundo ele, poderia ser muito útil aos colonos que tivessem acesso à leitura. ${ }^{40}$ Pois, por meio de tal sistema, no mesmo ano da publicação desse texto em Lisboa, o mencionado tradutor foi nomeado lente em um curso médico destinado a preparar pessoas interessadas em exercer a arte de curar e partejar em Vila Rica, como retribuição da sua idéia e do seu trabalho de traduzi-lo. Afinal, no prefácio da tradução, ele a apresentou ao soberano como "um serviço grato a Vossa Alteza Real", justificando-se que com ela buscava contribuir para diminuir a mortalidade da parte "mais útil e mais desvalida da população dos seus senhorios da América", na esperança de, com "este

38 DAZILLE, Jean Barthelemy. Observações sobre as enfermidades dos negros, abertura.

39 Belo Horizonte. Arquivo Público Mineiro (APM). Seção Colonial, Códice 295, 19/06/1799, p.8

40 Esse conceito de sistema régio de mercês foi elaborado com base em FRAGOSO, João. (org.) O Antigo Regime nos trópicos. Rio de Janeiro: Civilização Brasileira, 2001, p.48. 
cordial tributo" do seu "fiel e humilde obséquio", ter "acertado em agradar o melhor dos príncipes". ${ }^{41}$

Com isso percebe-se que, por um lado, a iniciativa de Antônio José Vieira de Carvalho para traduzir o manual de Dazille sobre enfermidades dos negros explica-se pelas suas ambições pessoais. Mas, por outro, ela é exemplo do empenho intelectual em curso em Portugal nas décadas finais do século XVIII destinado a promover reformas para incrementar a sua economia, o qual a seguir será esboçado com o objetivo de situar tal iniciativa no contexto que a motivou.

Um dos marcos mais significativos desse empenho é a criação da Academia Real das Ciências de Lisboa em 1779. Em seu abrigo foram redigidas as Memórias econômicas, as quais, de acordo com José Luís Cardoso, responsável pela sua reedição mais atual, tinham como objetivo a "realização de um inventário dos recursos e capacidades produtivas" no Reino e seus domínios de além-mar. Inventário de que se esperava poder revelar a essência dos problemas "que impediam o pleno exercício das funções econômicas essenciais" desses territórios, como a redução da extração de ouro em Minas Gerais, e apresentar soluções para superá-los. ${ }^{42}$ Entre esses domínios, destaca-se a Capitania de Minas Gerais, em particular as suas preciosas áreas de mineração, por causa da sua importância essencial para a economia portuguesa, onde, em uma delas, Vila Rica, atuava o responsável pela tradução do manual médico em tela.

Nas referidas áreas, a extração de ouro entrou em franca decadência na segunda metade do século XVIII, devido ao inevitável esgotamento das tão cobiçadas jazidas que estavam ao alcance dos recursos técnicos disponíveis na época para esse tipo de atividade que, no seu apogeu, havia atraído milhares de pessoas.

Por esse motivo, muitos colonos estavam migrando para outras regiões mais vantajosas economicamente, deslocando consigo fatores de produção até então concentrados na exploração dos veios auríferos, entre os quais os seus negros. Isso na visão do governador Luís da Cunha Meneses era um dos fatores da diminuição da mineração, conforme argumentou ao tomar decisões para conter o problema, como a que está expressava em um edital lançado em 1786:

Faço saber aos que este meu edital virem, ou dele notícia tiverem, que sendome constante o grande número de Escravos aplicados em minerais que desta capitania tem saído, por cujo motivo irá experimentar esta mesma capitania uma grande decadência no seu Real Quinto, ordeno que toda pessoa de qualquer

41 DAZILLE, Jean Barthelemy. Observações sobre as enfermidades dos negros, carta publicada na abertura da tradução.

42 CARDOSO, José Luís (org.). Memórias económicas inéditas. Lisboa: Publicações do II Centenário da Academia de Ciências de Lisboa, 1987, p.18. 
qualidade ou graduação for, que depois da publicação deste meu edital comprar os ditos escravos para o sobredito fim, será preso à minha ordem na cadeia desta capital. ${ }^{43}$

Um dos resultados disso foi a elevação do preço dos cativos nos núcleos urbanos estruturados em função de tal atividade econômica, como advertiu um observador da época em uma Memória sobre a utilidade pública em se tirar o ouro das minas, e os motivos dos poucos interesses dos particulares, que o mineram atualmente no Brasil, na qual aponta outro fator que explica tal elevação: os excessos tributários que incidiam no valor final dos africanos, alvos da "capitação desde a costa da África", cujos braços vinham "captados em somas que eles não pagariam por muito tempo que durassem". ${ }^{44}$

Aos contextos específicos da história econômica de Portugal e de Minas Gerais no final do século XVIII, soma-se o acúmulo das objeções à escravidão e ao tráfico de africanos, desde a publicação da obra Do espírito das leis (1748) de Montesquieu. Entre elas, um dos melhores exemplos são as críticas de Jaucourt, como a condenação a esse tipo de comércio como "um caso claro de desumanidade", no artigo Traite des nègres inserido no volume lançado em 1765 da Enciclopédia dirigida por Denis Diderot e Jean d'Alembert.

Em meio a esse acúmulo, começaram a surgir panfletos com mais intensidade nos Estados Unidos cobrando dos seus cidadãos a mesma liberdade que os havia impelido à guerra contra a Inglaterra para os seus escravos, engrossando um movimento que, no outro lado do Atlântico norte, estimulou as primeiras sociedades abolicionistas. ${ }^{45}$

As repercussões desse movimento, em meio aos efeitos da deflagração da Revolução de São Domingos em 1791, liderada e vencida pelos negros, colaboraram também em Portugal para despertar preocupação com as condições de vida da população cativa, pelo menos no plano do discurso, da qual resultou elaboração de uma Memória a respeito dos escravos e tráfico da escravatura entre a costa da África e o Brasil, lida em 1793 por Luís Antônio de Oliveira Mendes na Academia Real das Ciências de Lisboa. Com o objetivo de inventariar as doenças que mais freqüentemente acometiam "os pretos recém-tirados da África, examinando as causas da sua mortalidade depois da sua chegada ao Brasil", para diminuir "tanto estrago e,

43 APM. Seção Colonial. Códice 214, 01/12/1786, p.14v.

44 LEME, Antônio Pires da Silva Pontes. Memória sobre a utilidade pública em se tirar o ouro das minas, e os motivos dos poucos interesses dos particulares, que o mineram atualmente no Brasil. Apud: CARDOSO, José Luís. (org.) Memórias económicas inéditas, p.326-8. O aumento dos preços dos escravos de fato havia ocorrido nas áreas mineradoras, como mostrou BEGARD, Laird. Mariana Depois do boom: aspectos demográficos e econômicos da escravidão em Mariana, 1750-1808. Estudos Econômicos, v.24, n.3, p.513-520, 1994.

45 DAVIS, David Brion. The problem of slavery in the age of revolution (1770-1823). New York: Ithaca, 1975 e BAILYN, Bernard. As origens ideológicas da Revolução Americana. Bauru: Edusc, 2003. 
finalmente, indicar os métodos mais apropriados para evitá-lo, prevenindo-o e curando-o", ele justificou o seu texto da seguinte maneira:

Entre os projetos, em que se tem desde a sua origem, e estabelecimento empregado esta Real Academia, nenhum é mais digno de louvor do que o presente que foi dado para discorrer-se: porque ao tempo, em que ela compadecida se manifesta numa perfeita, e verdadeira amiga desta porção mais desgraçada da espécie humana, consultando em geral os interesses dos pretos recém-tirados dos reinos africanos para o Brasil, na preservação das suas vidas; consulta também em particular o dos seus senhores, que, por efeito da compra, de contínuo arriscam o seu valor, e importância, que com aqueles se sepulta: e em comum os do Estado, que sabe, e pesa que eles são tanto mais preciosos, quanto necessários para a estabilidade e promoção da agricultura, e das diferentes manufaturas nos domínios Ultramar. ${ }^{46}$

Nessa justificativa, percebe-se a mesma articulação entre riqueza nacional e o crescimento da população como fundamento da necessidade de se melhorar a vida dos escravos presente nos textos coetâneos dedicados a esse assunto, de forma que a sua Memória pode ser um exemplo do que Fernando Novais chamou de mercantilismo ilustrado. ${ }^{47}$ Desse modo, sem questionar a escravidão, aquele autor procurou mostrar ao governo, aos traficantes e aos colonos o que poderiam fazer para evitar tantas mortes de escravos nos navios negreiros e nos estabelecimentos coloniais, uma vez que "a causa de toda sua grande mortandade e estrago, além das outras causas que menos concorre, é o modo por que são tratados". ${ }^{48}$ Ao primeiro sugeriu fiscalização dos embarques de negros na costa africana, cobrando taxas por cada cabeça embarcada, de forma a impedir que as embarcações ficassem lotadas, porque isso aumentava as mortes em altomar. Aos segundos propôs mais cuidado com a qualidade e quantidade dos mantimentos e da água durante a travessia, pois assim evitariam muitas perdas, o que seria "mais concordante com os seus próprios interesses". E aos últimos recomendou melhor tratamento dos seus escravos, fornecendo-Ihes alimentação, vestuário, moradia e descanso adequados, pois se essas sugestões fossem acolhidas, "pouca ou nenhuma escravaria viria a falecer das suas ordinárias doenças". ${ }^{49}$

Todas essas propostas deveriam ser colocadas em prática, porque, como explicou o seu autor a respeito da sua importância: "Que havendo

46 MENDES, Luís Antônio de Oliveira. Memória a respeito dos escravos e tráfico da escravatura entre a costa da África e o Brasil. Apud: CARDOSO, José Luís. (org.) Memórias económicas da Academia Real das Ciências de Lisboa (1789-1815). Lisboa: Banco de Portugal, 1991, tomo IV, p.7.

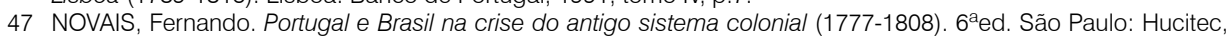
1995, p.230

48 MENDES, Luís Antônio de Oliveira. Memória a respeito dos escravos e tráfico da escravatura entre a costa da África e o Brasil, p.8.

49 MENDES, Luís Antônio de Oliveira. Memória a respeito dos escravos e tráfico da escravatura entre a costa da África e o Brasil, p.39-43. 
uma rigorosa necessidade da mesma escravatura para promoção das nossas fábricas e estabelecimento no Brasil, de onde nos vêm copiosos e abundantíssimos gêneros, e nos quais a real coroa percebe seus justos e devidos direitos," logo "a humanidade e os interesses da mesma real coroa exigem que se resista a esses absurdos" cometidos contra os escravos..$^{50}$

É nesse quadro da situação econômica de Portugal, em particular da crise da exploração aurífera em Minas Gerais, e do esforço intelectual para melhorá-la, acrescido das pressões dos autores ilustrados contra a escravidão, do aumento dos preços dos escravos e das constatações da Memória anteriormente apresentada, que se insere a tradução do cirurgiãomor Antônio José Vieira de Carvalho do manual médico de Dazille sobre enfermidades dos negros e a sua publicação sob o patrocínio régio. Em outras palavras, essa convergência de fatores em um mesmo contexto histórico, marcado por profundas transformações, explica o interesse médico e o governamental em divulgar na Colônia um livro contendo informações para a redução dos altos índices de óbitos da população escrava.

Assim, o texto, no qual tal cirurgião expõe os motivos que o levaram a se empenhar para traduzir uma obra francesa sobre as doenças mais comuns dos negros, pode ser interpretado como ressonância intelectual das preocupações de uma época caracterizada pela reflexão crítica dos seus problemas e pela crença na capacidade de superá-los por meio da razão. Eis o seu conteúdo que, pela relevância de suas afirmações para a compreensão do papel que o saber médico poderia exercer na duração da vida útil do escravo e, com efeito, na prosperidade econômica colonial e metropolitana, segue exposto inteiramente:

Felizmente o meu destino me havia levado a ocupar nas Minas Gerais o emprego de Cirurgião-mor do Regimento da Cavalaria que guarnece a capital desta capitania, onde exercendo, a par de minha profissão, a Medicina prática, pude ver com meus mesmos olhos quanto a espécie humana sofre na inumerável multidão dos negros, que ali transporta a escravidão e o comércio. A mudança do clima, a diferença de tratamento, um trabalho contínuo e desmedido, e até a fome raríssimas vezes interrompida, juntos à triste consideração de seu penoso estado, são outras tantas causas das singulares e gravíssimas enfermidades, a que é sujeita entre nós esta raça desventurada de homens; que fazendo-lhes a vida pesada e adiantando-lhes a morte, levam à sepultura o melhor dos cabedais daquela e de outras Colônias da América Portuguesa, enterrando com eles o mesmo ouro que os seus braços haviam desenterrado, e secando assim na sua origem um dos primeiros mananciais da Coroa e do Estado. Estimulado, pois desta fatal experiência e do sincero e ardentíssimo desejo de me dar todo ao serviço de Vossa Alteza Real, me subministrou o meu zelo a lembrança de traduzir para Língua Portuguesa o Tratado que sobre as moléstias dos Negros ordenara e escrevera na llha de

50 MENDES, Luís Antônio de Oliveira. Memória a respeito dos escravos e tráfico da escravatura entre a costa da África e o Brasil, p.50. 
São Domingos Mr. Dazille; obra que tendo merecido a aprovação e os louvores de uma Nação tão ilustre, como iluminada enquanto não desvairou da Razão, e de sua nativa lealdade, me serviu de guia na minha prática, e a qual, divulgada por meio deste tratado, pode vir a ser de muito uso em todo o Estado do Brasil, onde, pela analogia de muitas circunstâncias físicas e morais são aplicáveis às observações e às doutrinas de seu Autor; e onde a dificuldade de recursos, pelas imensas distâncias que separam os seus habitantes, e pela raridade de médicos, fazem que pela maior parte o seja cada um em sua casa. ${ }^{51}$

Mas, como aceitando a escravidão, quando ela estava sendo questionada, esse texto ressoa o pensamento crítico e racional da llustração? Em primeiro lugar, conforme mostrou David Brion Davis, o racionalismo foi ambivalente, pois as mesmas idéias que serviram de base para proposição da abolição do trabalho escravo também foram mobilizadas para defendêlo. Em segundo lugar, conforme mostrou Maxwell, o lluminismo em Portugal apresentou características paradoxais, porque serviu antes para o fortalecimento do poder do Estado e do sistema colonial e não para extensão das liberdades individuais. ${ }^{52}$

Dessa forma, os seus argumentos, em sintonia com as referidas contradições, sintetizam o ideário, formado pela relação entre sentimento humanitário e interesse econômico, que norteou as elites médicas da segunda metade do século XVIII à construção de textos apresentando uma preocupação inédita com as enfermidades dos escravos. Preocupação essa que estava relacionada essencialmente com a saúde do próprio sistema colonial, devido à sua alta dependência do tráfico de africanos em uma época em que essa atividade comercial estava sendo cada vez mais contestada.

Enfim, a llustração e as críticas dos seus escritores á escravidão e ao tráfico de africanos exerceram, junto com os desarranjos econômicos provocados durante a crise do Antigo Regime, decisiva influência na elaboração de textos médicos sobre as causas e as formas de tratamento das doenças da população escrava. Influência essa que continuou sendo exercida nos médicos que escreveram sobre as condições de vida dos escravos no século XIX, principalmente nos que atuavam nas sociedades cuja economia permaneceu dependente do tráfico transatlântico de africanos para reposição da sua mão-de-obra, como no Brasil, onde, em decorrência da morosidade para se extinguir de fato tal tipo de comércio, bem como da ampla oferta de indivíduos que por meio dele foram arrastados como mercadorias humanas e com preços baixos, os índices de óbitos da população cativa permaneceram altos.

51 Apud: DAZILLE, Jean Barthelemy. Observações sobre as enfermidades dos negros, abertura da obra.

52 DAVIS, David Brion. The problem of slavery in the age of revolution (1770-1823), p.435 e MAXWELL, Kenneth. Marquês de Pombal: paradoxo do lluminismo. Rio de Janeiro: Paz e Terra, 1997, p.170. Conforme revelou MARQUESE, Rafael de Bivar. Feitores do corpo, missionários da mente, p.93, a ambivalência do racionalismo marcou vários escritos em todas as partes da América onde a reforma da administração do trabalho escravo estava em debate. 